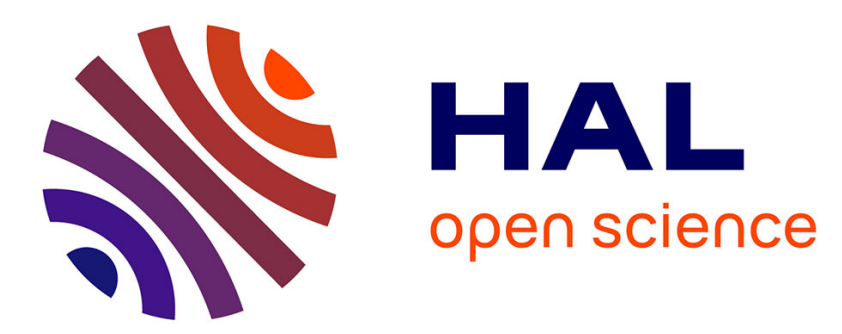

\title{
Electronic structure and peculiar bonding properties of NdNiMg5 from first principles
}

Samir F. Matar, Bassem Ourane, Etienne Gaudin, Jean-Louis Bobet, Adel F. Al Alam, Naim N. Ouaini

\section{> To cite this version:}

Samir F. Matar, Bassem Ourane, Etienne Gaudin, Jean-Louis Bobet, Adel F. Al Alam, et al.. Electronic structure and peculiar bonding properties of NdNiMg5 from first principles. Solid State Sciences, 2014, 38, pp.1-6. 10.1016/j.solidstatesciences.2014.09.006 . hal-01071493

\section{HAL Id: hal-01071493 \\ https://hal.science/hal-01071493}

Submitted on 14 Oct 2014

HAL is a multi-disciplinary open access archive for the deposit and dissemination of scientific research documents, whether they are published or not. The documents may come from teaching and research institutions in France or abroad, or from public or private research centers.
L'archive ouverte pluridisciplinaire HAL, est destinée au dépôt et à la diffusion de documents scientifiques de niveau recherche, publiés ou non, émanant des établissements d'enseignement et de recherche français ou étrangers, des laboratoires publics ou privés. 
Accepted with Elsevier (Solid State Sciences) Sept.15 2014

Electronic structure and peculiar bonding properties of $\mathrm{NdNiMg}_{5}$ from first principles.

Samir F. Matar ${ }^{1}$,* Bassem Ourane ${ }^{1}$, Etienne Gaudin ${ }^{1}$, Jean-Louis Bobet ${ }^{1}$, Adel F. Al Alam², Naïm Ouaini².

1CNRS, Université de Bordeaux, ICMCB. 33600 Pessac. France.

²Université Saint Esprit de Kaslik, CSR-USEK, CNRS_L, Jounieh, Liban.

*Corresponding author: matar@icmcb-bordeaux.cnrs.fr ; abouliess@gmail.com

Keywords: Intermetallics. Magnetism. DFT. Cohesive energy. Elastic properties. Chemical bonding.

Dedication: This work is dedicated to Professor René Otayek.

\begin{abstract}
:
The newly found ternary compound $\mathrm{NdNiMg}_{5}$ has been studied within DFT based methodologies. Results of cohesive energy, charge transfers, elastic constants and electron localized function mapping as well as electronic structure and bonding properties have been compared with those of isostructural binary $\mathrm{NdNi}$. The calculation results have shown that $\mathrm{Mg}$ substructures interlayering $N d N i$-like slabs exhibit different magnitudes of charge transfers all within range of metallic behavior and the different $\mathrm{Mg}$ sublattices structures selectively bind with $\mathrm{Nd}$ and $\mathrm{Ni}$ substructures. As a consequence an enhanced cohesion with respect to binary intermetallic $\mathrm{NdNi}$ is identified. The whole set of elastic constants and their combinations in orthorhombic symmetry confirm the mechanical stability of $\mathrm{NdNiMg}_{5}$ with larger compressibility and less ductility (more brittleness) with respect to NdNi. While in an intermetallic compound such as $\mathrm{NdNi}$ the bonding is ensured by $\mathrm{Nd}-\mathrm{Ni}$ interaction, in $\mathrm{NdNiMg}_{5} \mathrm{Nd}-\mathrm{Ni}, \mathrm{Nd}-\mathrm{Mg}$, Ni-Mg as well as $\mathrm{Mg}-\mathrm{Mg}$ participate to the bonding and the extra electrons brought by $\mathrm{Mg}$ are found within bonding states thus illustrating furthermore the enhanced cohesion of the ternary versus the binary systems.
\end{abstract}




\section{Introduction}

Magnesium rich compounds are of interest in the field of materials science for crystal chemistry fundamentals [1,2] and for different applications such as corrosion resistance compounds within the Mg-Zn-RE ternary (RE: Rare Earth) [3] and host compounds for hydrogen storage in the solid state $[4,5]$. The ternary compound $\mathrm{LaCuMg}_{4}$ can be considered from the crystal chemistry point of view as $\mathrm{Mg}$ inserted $\mathrm{LaCuMg}$ [6]. While exploring the $\mathrm{Mg}$ rich side of $\mathrm{Mg}-\mathrm{Nd}-\mathrm{Ni}$ ternary phase diagram Ourane et al. discovered the $\mathrm{Mg}$ rich ternary $\mathrm{NdNiMg}_{5}$ [7] characterized by a new unusual structure and a long range antiferromagnetic order. Whereas the ternary $\mathrm{NdNiMg}$ does not exist, i.e. oppositely to the $\mathrm{LaCuMg}$ ternary, $\mathrm{NdNiMg}_{5}$ can be structurally described as $\mathrm{Mg}$ inserted $\mathrm{NdNi}$ intermetallic with interpenetrating networks of $\mathrm{Mg}$ and largely separated $\mathrm{NdNi}(c / 2 \sim 6.9 \AA)$. This can be visualized in a projection of the structure given in Fig. 1 stressing the succession of NdNi and $\mathrm{Mg}$ layers along the long orthorhombic $c$ axis. Also the base centered orthorhombic symmetry with $\mathrm{Cmcm}$ space group of the intermetallic $\mathrm{NdNi}$ is also found in the $\mathrm{Mg}$ rich ternary. $\mathrm{Mg}$ $\mathrm{Mg}$ distances are in the range of $\sim 3 \AA$ close to the sum of $\mathrm{Mg}$ metallic radii so that one may expect metallic like $\mathrm{Mg}$ network. Short $\mathrm{Mg}-\mathrm{Mg}$ connections are found in ternary magnesiumrich compounds within the $\mathrm{Ce}-\mathrm{Ru}-\mathrm{Mg}$ ternary phase diagram as $\mathrm{CeRu}_{2} \mathrm{Mg}_{5}$ and $\mathrm{Ce}_{2} \mathrm{Ru}_{4} \mathrm{Mg}_{17}$ compositions [8]. However the schematic view in Fig. 1 of $\mathrm{NdNiMg}_{5}$ merely gives a qualitative description of the structure due to the belonging of magnesium to three different substructures designated in Fig. 1 with different distances to $\mathrm{Nd}$ and $\mathrm{Ni}$ (cf. Table 1). Consequently the propose of the present work is to provide a quantitative assessment of the electronic and magnetic structures and of the peculiar bonding properties of $\mathrm{NdNiMg}_{5}$ with respect to $\mathrm{NdNi}$ within computations carried out in the well established framework of the quantum density functional theory (DFT) $[9,10]$.

\section{Computational details}

Two computational methods within the DFT were used in a complementary manner. The Vienna ab initio simulation package (VASP) code [11,12] allows geometry optimization, charge transfer trends and cohesive energy calculations. For this we use the projector augmented wave (PAW) method [13], with the generalized gradient approximation (GGA) scheme following Perdew, Burke and Ernzerhof (PBE) [14]. 
Semi-core $2 p^{6}$ states were considered upon building the PAW Mg potential. The conjugategradient algorithm [15] is used in this computational scheme to relax the atoms. The tetrahedron method with Blöchl corrections [13] as well as a Methfessel-Paxton [16] scheme was applied for both geometry relaxation and total energy calculations. Brillouin-zone (BZ) integrals were approximated using special k-point sampling [17]. The optimization of the structural parameters was performed until the forces on the atoms were less than $0.02 \mathrm{eV} / \AA$ and all stress components less than $0.003 \mathrm{eV} / \AA^{3}$. The calculations are converged at an energy cut-off of $400 \mathrm{eV}$ for the plane-wave basis set with respect to the k-point integration up to 12 $\times 12 \times 4\left(\mathrm{k}_{\mathrm{x}}, \mathrm{k}_{\mathrm{y}}, \mathrm{k}_{\mathrm{z}}\right)$ for best convergence and relaxation to zero strains. The calculations are scalar relativistic. From the calculations, an illustration of the electron distribution is accessed from the electron localization function (ELF) [18]. ELF is a normalized function between 0 (zero localization, blue zones) and 1 (strong localization, red zones) with the value of $1 / 2$ corresponding to a free electron gas behavior (green zones) -cf. Fig. 2. Also an analysis of the charge density is done with the approach of "atoms in molecules and crystals" (AIM) introduced by Bader [19] whereby molecules are divided into atoms. Following Bader, each atom in the compound is surrounded by a surface running through minima of the charge density. Then the total charge of an atom is determined by integration within the Bader region. Such an analysis can be useful when trends of charge transfer are sought; they do not constitute a tool for evaluating absolute ionizations. In the presently studied compound we evaluate the changes in total charges between title compound $\mathrm{NdNiMg}_{5}$ and the intermetallic $\mathrm{NdNi}$.

Subsequent all-electrons calculations with the GGA were carried out for a full description of the electronic structure and the properties of chemical bonding, using the augmented spherical wave (ASW) method devised by Williams, Kübler and Gelatt in 1979 [20,21] as a linearized method close to LMTO (Linearized Muffin Tin Orbitals). The ASW method has benefited from continuous developments leading to full potential FP-ASW with implementation of chemical bonding according to different schemes (cf. text book by V. Eyert [22] and therein references). The ASW method uses a minimal basis set for the valence states with the outermost shells representing one of each kind: the valence states and the matrix elements are constructed using partial waves up to $l_{\max }+1=4$ for $\mathrm{Nd}$; $l_{\max }+1=3$ for $\mathrm{Ni}$ and $l_{\max }+1=2$ for $\mathrm{Mg}$. Self-consistency is achieved when charge transfers and energy changes between two successive cycles were below $10^{-8}$ and $10^{-6} \mathrm{eV}$, respectively. BZ integrations were performed using the linear tetrahedron method within the irreducible wedge. Calculation are first carried 
out for a non magnetic, spin degenerate configuration (NSP) for assessing the instability of the electronic system towards magnetic polarization and for examining the properties of chemical bonding, then spin polarized (SP) calculations are carried out for two spin channels $\uparrow$ and $\downarrow$ in an implicit ferromagnetic order (SP-F), with four $f$-electrons for $\mathrm{Nd}$, the $4 f$-subshell is only partially filled. From this, the single particle scheme of the GGA is good enough concerning electronic correlations as shown in Ce-based [23] and $\mathrm{Nd}$ based [24] intermetallic compounds. This is with respect to possible improvements with the introduction of a Coulomb on site repulsion parameter within so called GGA+U scheme [25]. Such preliminary calculations were carried out to check this point. They showed only a small departure from the single particle picture, e.g. for the lowering of the $4 f$ density of states (DOS) at the Fermi level, pushing it down in energy. Lastly for modeling the ground state found antiferromagnetic by experiment [7], SP-AF calculations were done by considering half subcell as "SPIN UP" and the other half as "SPIN DOWN". Besides the site and spin projected density of states, we discuss qualitatively the pair interactions based on the overlap population analysis with the crystal orbital overlap population (COOP) [26]. In the plots, positive, negative, and zero COOP indicate bonding, anti-bonding, and non-bonding interactions, respectively.

\section{Geometry optimization results.}

\section{Geometry optimization and relative charge transfers.}

Starting from the experimental structure parameters of $\mathrm{NdNiMg}_{5}$ [7] and $\mathrm{NdNi}$ [27] given in Table 1, unconstrained geometry optimization runs were carried out. In both compounds the orthorhombic symmetry in $\mathrm{Cmcm}$ space group is preserved after successive calculations with increasing precision of the BZ. As shown in Table 1, the fully relaxed structure parameters are found close to starting ones and the shortest interatomic distances are in agreement with experiment. Especially $\mathrm{d}(\mathrm{Nd}-\mathrm{Ni})$ is smaller in the ternary and the shortest metal-magnesium connections are for $\mathrm{Nd}-\mathrm{Mg} 1$ and $\mathrm{Ni}-\mathrm{Mg} 2 . \mathrm{Mg} 3$ is at large separation from either $\mathrm{Nd}$ or $\mathrm{Ni}$. These observations let suggest different charge transfer trends $(Q)$ along the different substructure constituents. This can be analyzed from the charge density CHGCAR file obtained from the calculations using the AIM theory [19] introduced above applied to both the ternary and the binary compounds:

$\mathrm{NdNiMg}_{5}: Q(\mathrm{Nd})=+0.51, Q(\mathrm{Ni})=-0.98, Q(\mathrm{Mg} 1)=+0.10, Q(\mathrm{Mg} 2)=+0.02$ and $Q(\mathrm{Mg} 3) \sim 0$. 
NdNi: $Q(\mathrm{Nd})=+0.63, Q(\mathrm{Ni})=-0.63$.

Looking at the binary intermetallic the amount of charge transfer of \pm 0.63 is small as one would expect in an intermetallic compound. Charge flows from $\mathrm{Nd}$ to $\mathrm{Ni}$ and this follows the course of the respective electronegativities, larger for $\mathrm{Ni}$ versus $\mathrm{Nd}: \chi(\mathrm{Ni})=1.91 ; \chi(\mathrm{Nd})=$ 1.14. Its magnitude is significant of a covalent like bonding as one would expect from a metallic compound. In the ternary magnesium rich compound the charge imbalance is changed with a smaller positive charge on $\mathrm{Nd}$ and a much larger magnitude negative charge on $\mathrm{Ni}$ arising from the presence of neighboring $\mathrm{Mg}$, especially $\mathrm{Mg} 1$ which is charged +0.1 whereas $\mathrm{Mg} 2$ carries a small charge of +0.02 whereas $\mathrm{Mg} 3$ is nearly neutral. Also the smaller charge on $\mathrm{Nd}$ as with respect to its value in $\mathrm{NdNi}$, is due to the charge transfer from $\mathrm{Mg}$. Note that $\chi(\mathrm{Mg})=1.31$ is larger than Nd's but the major change in the Mg rich ternary is observed for $\mathrm{Ni}$.

\section{Electron localization function contours plots.}

We illustrate these results with electron localization function ELF shown in Fig. 2 for a slice crossing all constituents labeled with their belonging to the different sub-structures, especially $\mathrm{Mg}$. This projection resembles the sketch of the crystal structure given in Fig. 1. The strong electron localization around $\mathrm{Nd}$ arises from the inclusion of core electrons of filled subshells in the construction of the PAW potential. Green areas are found around Ni meaning that its negative charge obtained above is actually signaling a delocalized free electron-like behavior between the atomic constituents; this is also observed between $\mathrm{Ni}$ and $\mathrm{Nd}$ as well as between $\mathrm{Nd}$ and $\mathrm{Mg} 1$ with a metallic like bonding. Also the ELF contours extend from $\mathrm{Ni}$ to $\mathrm{Mg} 2$ (green to yellow) indicating the bonding between them as it is discussed here below with the COOP. Between $N d N i$-like layers the $\mathrm{Mg}$ sub-structures show the peculiar behavior of exhibiting strong localization (dark yellow, reddish spots). $\mathrm{Mg}-\mathrm{Mg}$ metallic bonding is then present as proposed in the introduction and the schematic behavior of a metallic $\mathrm{Mg}$ substructure interlayering $N d N i$ finds its illustration here.

\section{Cohesive energies.}

The question arises as to the role of $\mathrm{Mg}$ adjunction/insertion within $\mathrm{NdNi}$ in the stability of the binary. This should be quantified from examining the magnitudes of the cohesive energies. $E_{\text {coh. }}=E_{\text {total }}($ compound $)-\Sigma E$ (constituents). The energies of the constituents were 
calculated in their ground state structures. $\mathrm{Mg}$ (hexagonal, with $2 p^{6}$ semi-core states): -2.784 $\mathrm{eV}$ (2 atoms); $\mathrm{Nd}$ (hexagonal): $-9.48 \mathrm{eV}$ (2 atoms) and Ni (FCC): $-5.51 \mathrm{eV}$ (1 atom). Then $\mathrm{E}_{\text {coh. }}\left(\mathrm{NdNiMg}_{5}\right)=-1.59 \mathrm{eV} / \mathrm{FU}$ and $\mathrm{E}_{\mathrm{coh}}(\mathrm{NdNi})=-0.74 \mathrm{eV} / \mathrm{FU}$. This peculiar result translates the large stability provided to the binary intermetallic by $\mathrm{Mg}$ through covalent like bonding with $\mathrm{Nd}$ as well as $\mathrm{Ni}$.

\section{Elastic constants bulk and shear modules}

In orthorhombic symmetry there are nine independent elastic stiffness constants $C_{11}, C_{22}, C_{33}$, $\mathrm{C}_{44}, \mathrm{C}_{55}, \mathrm{C}_{66}, \mathrm{C}_{12} \mathrm{C}_{23}$ and $\mathrm{C}_{13}$. Most encountered compounds are polycrystalline with randomly oriented mono-crystalline grains so that on a large scale, such materials can be considered as statistically isotropic. They are then completely described by the bulk modulus $B$ and the shear modulus $G$, which may be obtained by averaging the single-crystal elastic constants. The most widely used averaging method of the elastic stiffness constants is Voigt's based on a uniform strain (cf. Ref. [25] for a review). The calculated set of elastic constants in $\mathrm{NiNdMg}_{5}$ and $\mathrm{NdNi}$ are given in Table 2. All nine $\mathrm{C}_{\mathrm{ij}}$ are positive. This condition and the positive magnitudes of $\mathrm{C}_{\mathrm{ij}}$ combinations pertaining to the stability [28,29] are obeyed. Comparative mechanical properties are obtained from the calculations of the respective bulk and shear modules, $B \mathrm{~V}$ and $G_{\mathrm{V}}$ following Voigt and formulated as follows:

$B v=1 / 9\left\{\left(\mathrm{C}_{11}+\mathrm{C}_{22}+\mathrm{C}_{33}+\mathrm{C}_{33}\right)+2\left(\mathrm{C}_{12}+\mathrm{C}_{23}+\mathrm{C}_{13}\right)\right\}$ and

$G \mathrm{v}=1 / 15\left(\mathrm{C}_{11}+\mathrm{C}_{22}+\mathrm{C}_{33}+\mathrm{C}_{33}\right)-1 / 15\left\{\left(\mathrm{C}_{12}+\mathrm{C}_{13}+\mathrm{C}_{23}\right)-3\left(\mathrm{C}_{44}+\mathrm{C}_{55}+2 \mathrm{C}_{66}\right)\right\}$

The numerical values are given in Table 2. NdNi intermetallic has a bulk modulus of $60 \mathrm{GPa}$, i.e. within range of other nickel based binary intermetallics [30]; its magnitude is larger than the calculated value for the ternary $\mathrm{NdNiMg}_{5}$. This can be explained by the larger unit cell volume thanks to the insertion of a light and compressible element $\mathrm{Mg}$ with $B=45 \mathrm{GPa}$. On the opposite the trends of shear modules are inverted implying less elasticity of the ternary. As shown in the ELF plots (Fig. 2) Mg brings covalent like bonding besides the metallic bonds of NdNi. Such bonds hinder the gliding of (NdNi) planes with respect to each other. This is further confirmed by the corresponding $G \mathrm{v} / B \mathrm{~V}$ ratio which is an indicator of brittleness/ductility: $G / B\left(\mathrm{NdNiMg}_{5}\right)=0.51$ whereas $G / B(\mathrm{NdNi})=0.39$. Knowing that ductile metals have $G / B$ ratios in the range $0.4-0.2$ [31]; it can be concluded that $\mathrm{NdNiMg}_{5}$ is less 
ductile (more brittle) than NdNi. This further confirms the role of the covalent bonding which is discussed hereafter.

\section{All electrons non magnetic and magnetic calculations and chemical bonding.}

Focusing on $\mathrm{NdNiMg}_{5}$ we now investigate its electronic and magnetic structures as well as the bonding properties. In spite of its experimentally identified antiferromagnetic (AF) ground state [7], the calculations are firstly done for spin degenerate, non spin polarized (NSP), configuration using the experimental crystal data with repeated runs at increasing BZ integration precision. Such a first study allows examining the atom resolved origin of magnetic instability on one hand and permits qualitative description of the chemical bonding based on the overlap populations $\mathrm{S}_{\mathrm{ij}}$, on the other hand. Then spin polarized (SP) calculations are done unbiased, i.e. starting from two equal spin populations ( $\uparrow$ and $\downarrow$ ). In fact the SP self consistent computations can lead either to finite magnetization within an implicit long range ferromagnetic order (SP-F) with a stabilization of the energy due to magnetic exchange or to zero magnetization with equal energy to the NSP configuration. Lastly the magnetic ground state, SP-AF is obtained staring from SP-configuration by splitting the unit cell into two magnetic subcells with one as 'UP SPIN' and the other subcell as 'DOWN SPIN'.

\section{Electronic and magnetic structures}

At self consistent convergence of the charges and of the (variational) energy, the amount and the sign of charge transfer are similar to the Bader analysis above. The site projected densities of states (PDOS) are displayed in Fig. 3a. The zero energy along the $x$ axis is taken with respect to the Fermi energy $\left(\mathrm{E}_{\mathrm{F}}\right)$. The valence band $(\mathrm{VB})$ is characterized by Ni $d$ states centered at $-2 \mathrm{eV}$ and $\mathrm{Nd} 4 f$ states lying in EF. Low intensity states are smeared over the $\mathrm{VB}$ as well as above $\mathrm{EF}_{\mathrm{F}}$ within the conduction band (CB). This is made more explicit Fig. $3 \mathrm{~b}$ where a narrower $y$-axis range shows the $\mathrm{Nd}$ and $\mathrm{Ni} p, d$ projected PDOS and the total $\mathrm{Mg}$ PDOS at the three structure sites. The broad and dispersed Mg states are observed with small differences between them as well as with $\mathrm{Nd}$ and $\mathrm{Ni}$ on one hand and between $\mathrm{Nd}$ and $\mathrm{Ni}$ on the other hand; see for instance the resembling Nd and Ni PDOS for a peak at $-2 \mathrm{eV}$ at which the Mg1 PDOS equally shows similar skyline PDOS. These observations allow casting a preliminary chemical bonding proposition involving metals $p, d$ states with $\operatorname{Mg} 1 s, p$. This is developed upon in next section. The large DOS's at EF signal a magnetic instability within the Stoner theory of band ferromagnetism [32]. This is uniquely due to $\mathrm{Nd} f$ states, i.e. excluding 
$\mathrm{Ni}$ whose $d$-sates lie completely within the VB. However if a magnetic moment develops on $\mathrm{Ni}$, it will be of induced nature due to the $\mathrm{Nd}-\mathrm{Ni}$ valence states quantum mixing.

Subsequent SP calculation actually lead to a large energy gain within an implicit ferromagnetic state with $\Delta \mathrm{E}(\mathrm{SP}-\mathrm{NSP})=-4 \mathrm{eV} / \mathrm{FU}$. The spin only magnetic moments are then in Bohr magnetons $\left(\mu_{\mathrm{B}}\right): \mathrm{M}(\mathrm{Nd})=3.15 ; \mathrm{M}(\mathrm{Ni})=-0.052 ; \mathrm{M}(\mathrm{Mg} 1)=0.025 ; \mathrm{M}(\mathrm{Mg} 2)=-0.006$; $\mathrm{M}(\mathrm{Mg} 3)=0.011 ; \mathrm{M}(\mathrm{FU})=3.22$. As expected from the NSP PDOS discussion, only Nd carries a proper magnetic moment whose magnitude approaches the effective moment value of 3.89 $\mu_{\mathrm{B}}$ on the contrary Ni has a small magnitude induced moment (negative sign). Also Mg's at the three sites carry small moments due to the bonding with the metal substructures. The site and spin projected DOS shown in Fig. 3c further illustrate these results by the large splitting between $\uparrow$ and $\downarrow$ Nd PDOS and the small shift between $\uparrow$ and $\downarrow$ Ni PDOS.

By enforcing SP-AF configuration as detailed above, the energy slightly decreases with respect to SP-F ( -1 eV/FU) which would suggest that the two configurations are close as interpreted on the basis of the small $\mathrm{T}_{\mathrm{N}}$ value of $12 \mathrm{~K}$ [7]. The moment on $\mathrm{Nd}$ is then $3.37 \mu \mathrm{B}$ closer to the effective moment value. The full compensation between the SPIN UP and SPIN DOWN magnetic subcells is illustrated in Fig. 3d.

\section{Chemical bonding}

The detailed PDOS panel in Fig. 3b clearly shows resembling PDOS between different species of the same chemical nature $(\mathrm{Nd}, \mathrm{Ni}, \mathrm{Mg} 1, \mathrm{Mg} 2, \mathrm{Mg} 3)$ as well as for species with different chemical natures thus pointing to the bonding between them. Such bonding is rationalized here based on the overlap matrix $S_{i j}$ elements within the COOP scheme [23]. For the first kind of interactions, Fig. 4a shows within the valence band low magnitude COOP for the different interactions, mainly $\mathrm{Nd}-\mathrm{Nd}$ and $\mathrm{Ni}-\mathrm{Ni}$ are weakest while there is non-negligible positive COOP (bonding) for $\mathrm{Mg} 2-\mathrm{Mg} 2$ and less for $\mathrm{Mg} 1-\mathrm{Mg} 1$ which show some negative antibonding COOP likely because of their involvement with the interaction with neighboring $\mathrm{Nd}, \mathrm{Ni}$ and as well as $\mathrm{Mg}$ belonging to the other sites. Then the bonding between species of the same kind is not significant for the overall cohesion of the structure except for Mg. Fig. 4b shows the COOP for the interaction between the different $\mathrm{Mg}$ substructures. They are more intense and show positive bonding COOP magnitudes. This clearly shows the contribution of $\mathrm{Mg}$ to the added cohesion of the compound with respect to NdNi. 
Regarding Nd-Ni bonding, we compare it with NdNi intermetallic (insert) in Fig. 4c showing lower magnitude of the $\mathrm{Nd}-\mathrm{Ni}$ bonding in the ternary. In as far as the $\mathrm{Nd}-\mathrm{Ni}$ distance is slightly smaller in the ternary (cf. Table 1), which should lead to reinforced Nd-Ni bonding, the argumentation cannot be based on distance consideration. It can be rather argued that the bonding of $\mathrm{Nd}$ and $\mathrm{Ni}$ with $\mathrm{Mg}$ susbstructures should be at the origin of this feature. Fig. $4 \mathrm{~d}$ shows such bonding exemplified for $\mathrm{Mg} 1$ and $\mathrm{Mg} 2$ substructures. Actually $\mathrm{Mg} 3$ sublattice contributes very small COOP. Indeed the major contributions arise from $\mathrm{Nd}-\mathrm{Mg} 1$ and $\mathrm{Ni}-\mathrm{Mg} 1$ which are of bonding nature throughout the $\mathrm{VB}$ and $\mathrm{NiMg} 2$ which shows bonding and antibonding (negative COOP in $1 \mathrm{eV}$ range below $\mathrm{E}_{\mathrm{F}}$ ). The positions of the COOP peaks corresponds with the PDOS (Fig. 3), mainly for Ni at the $\mathrm{d}$ PDOS peak at $\sim-2 \mathrm{eV}$ but also with a small contribution from $\mathrm{Nd} 4 f$ at $\mathrm{E}_{\mathrm{F}}$.

\section{Conclusions.}

In this work the electronic structure of the newly found $\mathrm{NdNiMg}_{5}$ intermetallic compound has been investigated ab initio within DFT. With respect to isostructural NdNi binary large changes brought by $\mathrm{Mg}$ have been found as to enhanced cohesive energy, larger compressibility and brittleness. The $\mathrm{Mg}$ substructures are found to retain a largely metallic behavior. Summing up on the bonding features, while in NdNi binary the bonding is ensured by $\mathrm{Nd}-\mathrm{Ni}$ interactions, in the ternary $\mathrm{NdNiMg}_{5}, \mathrm{Nd}-\mathrm{Ni}, \mathrm{Nd}-\mathrm{Mg}, \mathrm{Ni}-\mathrm{Mg}$ as well as $\mathrm{Mg}-\mathrm{Mg}$ participate to the bonding and provide increased cohesion to the crystal lattice as computed in former section thanks to the presence of the extra $(\mathrm{Mg})$ electrons into bonding states.

\section{Acknowledgements}

We acknowledge financial support from French-Lebanese CEDRE PHC project, CSR-USEK and CNRSL. Support from Conseil Régional d'Aquitaine. Computational facilities were provided by MCIA-Université de Bordeaux 


\section{References}

[1] U. Ch. Rodewald, B. Chevalier, R. Pöttgen. J. Solid State Chem. 180, 1720 (2007).

[2] S. Linsinger, R. Pöttgen, Z. Naturforsch., 66b, 565 (2011).

[3] D. Egusa, E. Abe, Acta Mater. 60, 166 (2012).

[4] S. Couillaud, E. Gaudin, J. L. Bobet, Intermetallics, 19, 336 (2011).

[5] S. Couillaud, E. Gaudin, J. Andrieux, S. Gorsse, M. Gayot, J.L. Bobet, Int. J. Hydrogen Energy, 37, 11824 (2012).

[6] P. Solokha, S. De Negri, V. Pavlyuka, A. Saccone, B.J. Marciniak, J. Solid State Chem., 180, 3066 (2007).

[7] B. Ourane, E.Gaudin, R. Zouari, S. Couillaud, J.-L. Bobet. Inorganic Chemistry 52, 13289 (2013).

[8] S.F. Matar, B. Chevalier, R. Pöttgen. Intermetallics 31, 88 (2012).

[9] W. Kohn, L.J. Sham, Phys. Rev. A, 1401133 (1964).

[10] P. Hohenberg, W. Kohn, Phys. Rev. B, 136, 864 (1965).

[11] G. Kresse, J. Furthmüller, Phys. Rev. B 54, 11169 (1996).

[12] G. Kresse, J. Joubert, Phys. Rev. B 59, 1758 (1999).

[13] P. E. Blöchl, Phys. Rev. B 50, 17953 (1994) and Phys. Rev. B 49, 16223 (1994).

[14] J. Perdew, K. Burke, M. Ernzerhof, Phys. Rev. Lett. 77, 3865 (1996).

[15] W.H. Press, B.P. Flannery, S.A. Teukolsky, W.T. Vetterling, Numerical Recipes, Cambridge University Press, New York (1986).

[16] M. Methfessel, A. T. Paxton, Phys. Rev. B 40, 3616 (1989).

[17] H.J. Monkhorst, J.D. Pack, Phys. Rev. B, 13, 5188 (1976).

[18] A. D. Becke, K. E. Edgecombe, J. Chem. Phys. 1990,92, 5397; and Nature 1994, 371, 683.

[19] R. Bader. Chem. Rev. 91, 893 (1991).

[20] A.R. Williams, J. Kübler, C.D. Gelatt Jr., Phys. Rev. B 19, 6094 (1979). 
[21] V. Eyert, Int. J. Quantum Chem., 77, 1007 (2000).

[22] V. Eyert, The Augmented Spherical Wave Method, Lect. Notes Phys. 849 (Springer, Berlin 2013).

[23] S. F. Matar, J. F. Riecken, B. Chevalier, R. Pöttgen, A. F. Al Alam, V. Eyert, Phys. Rev. B 76, 174434 (2007).

[24] S. Tencé, G. André, E. Gaudin, P. Bonville, A.F. Al Alam, S. Matar, W. Hermes, R. Pöttgen, B. Chevalier. J. Appl. Phys. 106, 033910 (2009).

[25] V. I. Anisimov, J. Zaanen, O.K. Andersen, Phys. Rev. B 44, 943 (1991).

[26] R. Hoffmann, Angew. Chem. Int. Ed. Engl., 26, 846 (1987).

[27 L. Zeng, H. F. Franzen, J. Alloys Compounds, 311, 226 (2000).

[28] S.F. Matar. Matériaux ultra-durs: Concepts et Modélisations. Série Techniques de l'ingénieur. T. I. Sciences et Techniques, Paris (2009) AF 6630 (20pp.)

[29]. O. Beckstein, J.E. Klepeis, G.L.W. Hart, O. Pankratov, Phys. Rev. B 63 (2001) 134112.

[30] S.F. Matar Solid State Sciences, 12, 59, (2010).

[31]. S. Kamran, K. Chen, L. Chen, L. Zhao J. Phys. Condens. Matter, 20, 085221 (2008),

[32] P. Mohn, Magnetism in the solid state - An introduction, springer series, in:

Solid-State Sciences. Springer, Heidelberg, 2003. 
Table 1. Experimental and calculated lattice parameters of $\mathrm{NdNiMg}_{5}$ and $\mathrm{NdNi}$. Lattice constants and distances are in units of $\AA$.

\begin{tabular}{|l|l|l|}
\hline $\begin{array}{l}\text { NdNiMg } 5 \\
\text { Cmcm, Z=4 FU }\end{array}$ & Exp. [7] & Calc. (this work) \\
\hline$a$ & 4.4799 & 4.4687 \\
\hline$b$ & 9.9827 & 10.0085 \\
\hline$c$ & 13.7854 & 13.7389 \\
\hline $\mathrm{V} / \AA^{37}$ & 616.5 & 614.47 \\
\hline $\mathrm{Nd}(4 c)$ & $1 / 2,0.10948,1 / 4$ & $1 / 2,0.110,1 / 4$ \\
\hline $\mathrm{Ni}(4 c)$ & $0,0.3254,1 / 4$ & $0,0.325,1 / 4$ \\
\hline $\mathrm{Mg} 1(8 f)$ & $1 / 2,0.40310,0.14140$ & $1 / 2,0.403,0.141$ \\
\hline $\mathrm{Mg} 2(8 f)$ & $0,0.20670,0.07662$ & $0,0.207,0.076$ \\
\hline $\mathrm{Mg} 3(4 b)$ & $1 / 2,0,0$ & $1 / 2,0,0$ \\
\hline $\mathrm{d}(\mathrm{Nd}-\mathrm{Ni})$ & 2.836 & 2.86 \\
$\mathrm{~d}(\mathrm{Nd}-\mathrm{Mg} 1)$ & 3.291 & 3.29 \\
$\mathrm{~d}(\mathrm{Nd}-\mathrm{Mg} 2)$ & 3.417 & 3.40 \\
$\mathrm{~d}(\mathrm{Ni}-\mathrm{Mg} 2)$ & 2.668 & 2.67 \\
\hline Energy $(\mathrm{eV}) / 2 \mathrm{FU}$ & & -37.61 \\
\hline
\end{tabular}

\begin{tabular}{|l|l|l|}
\hline $\begin{array}{l}\mathrm{NdNi} \\
\text { Cmcm, Z=4 FU }\end{array}$ & Exp. [24] & Calc. (this work) \\
\hline$a$ & 3.8059 & 3.8368 \\
\hline$b$ & 10.462 & 10.5599 \\
\hline$c$ & 4.3345 & 4.3563 \\
\hline $\mathrm{V} / \AA^{3}$ & 172.59 & 176.50 \\
\hline $\mathrm{Nd}(4 c)$ & $0,0.1385,1 / 4$ & $0,0.138,1 / 4$ \\
\hline $\mathrm{Ni}(4 c)$ & $0,0.4273,1 / 4$ & $0,0.428,1 / 4$ \\
\hline $\mathrm{d}(\mathrm{Nd}-\mathrm{Ni})$ & 2.916 & 2.93 \\
\hline Energy $(\mathrm{eV}) / 2 \mathrm{FU}$ & & -21.98 \\
\hline
\end{tabular}


Table 2 :Calculated elastic properties (in GPa units) of $\mathrm{NdNiMg}_{5}$ and $\mathrm{NdNi}$

\begin{tabular}{|c|c|c|}
\hline & $\mathrm{NdNiMg}_{5}$ & NdNi \\
\hline \multicolumn{3}{|l|}{$\mathbf{C}_{\mathbf{i j}}$} \\
\hline $\mathrm{C}_{11}$ & 79.7 & 78.4 \\
\hline $\mathrm{C}_{22}$ & 88.7 & 81.7 \\
\hline $\mathrm{C}_{33}$ & 68.4 & 88.4 \\
\hline $\mathrm{C}_{44}$ & 27.9 & 22.4 \\
\hline $\mathrm{C}_{55}$ & 26.6 & 33.3 \\
\hline $\mathrm{C}_{66}$ & 52.8 & 28.3 \\
\hline $\mathrm{C}_{12}$ & 45.3 & 38.1 \\
\hline $\mathrm{C}_{23}$ & 34.3 & 59.7 \\
\hline $\mathrm{C}_{13}$ & 51.7 & 45.4 \\
\hline \multicolumn{3}{|c|}{ Stability combinations } \\
\hline $\mathrm{C}_{11}+\mathrm{C}_{22}-2 \mathrm{C}_{12}$ & +77.8 & +83.9 \\
\hline $\mathrm{C}_{11}+\mathrm{C}_{33}-2 \mathrm{C}_{13}$ & +44.7 & +76.1 \\
\hline $\mathrm{C}_{22}+\mathrm{C}_{33}-2 \mathrm{C}_{23}$ & +88.5 & +50.7 \\
\hline \multicolumn{3}{|c|}{ Bulk $(B)$ and Shear $(G)$ modules } \\
\hline$B(\mathrm{GPa})$ & 55.5 & 60.3 \\
\hline$G(\mathrm{GPa})$ & 28.5 & 23.7 \\
\hline$G / B$ & 0.51 & 0.39 \\
\hline
\end{tabular}


Figures captions.

Fig. 1 : Sketch of the $\mathrm{NdNiMg}_{5}$ structure with a projection onto $b, c$ plane showing the succession of $N d N i$ and $\mathrm{Mg}$ layers.

Fig.2 Electron localization function (ELF) slice crossing all chemical species

Fig. $3 \mathrm{NdNiMg}$, site a) and b) and spin projected d) and e) DOS.

Fig. $4 \mathrm{NdNiMg}_{5}$, chemical bonding for the different interactions from COOP criterion. 


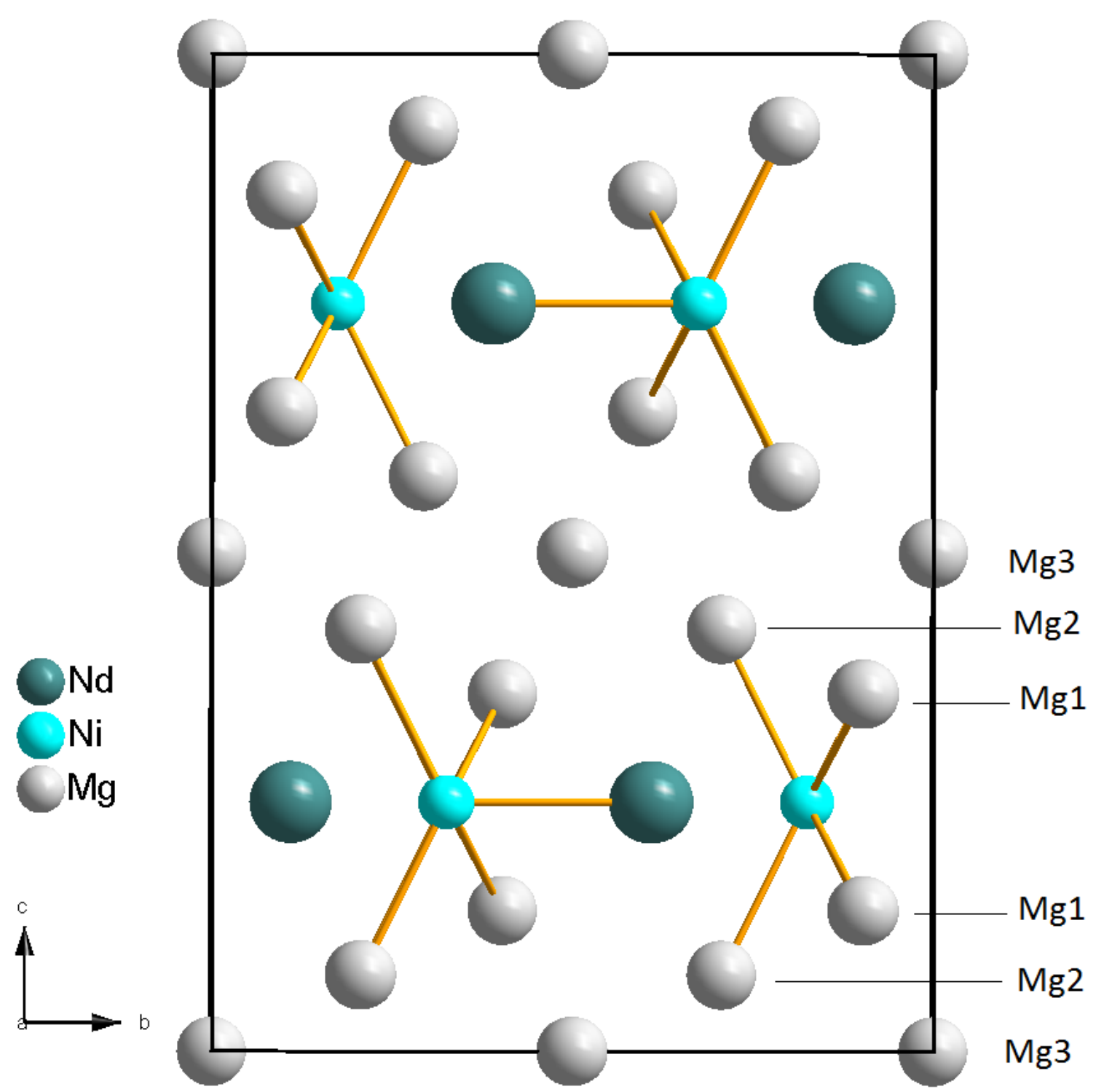

Fig. 1 


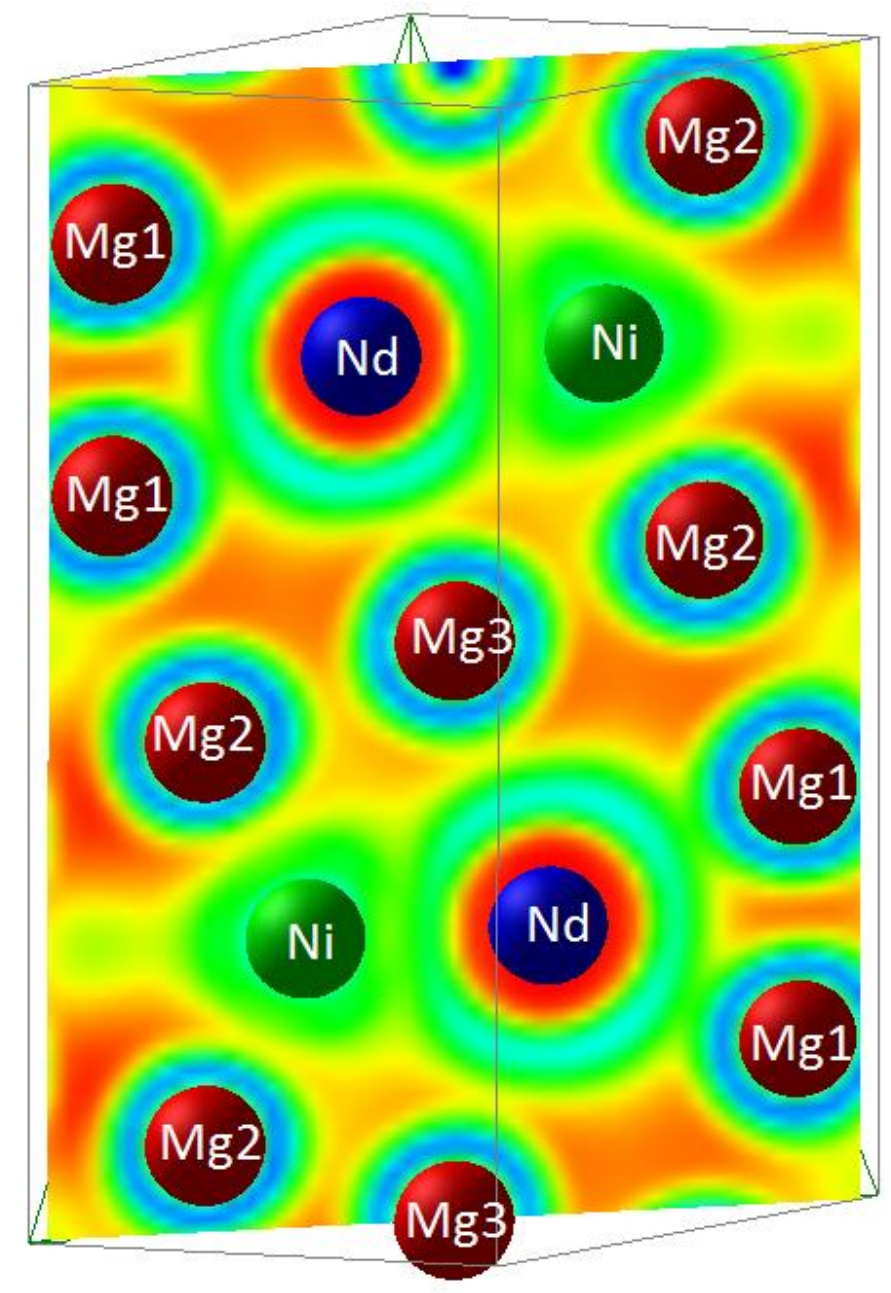

a) $\mathrm{NdNiMg}_{5}$

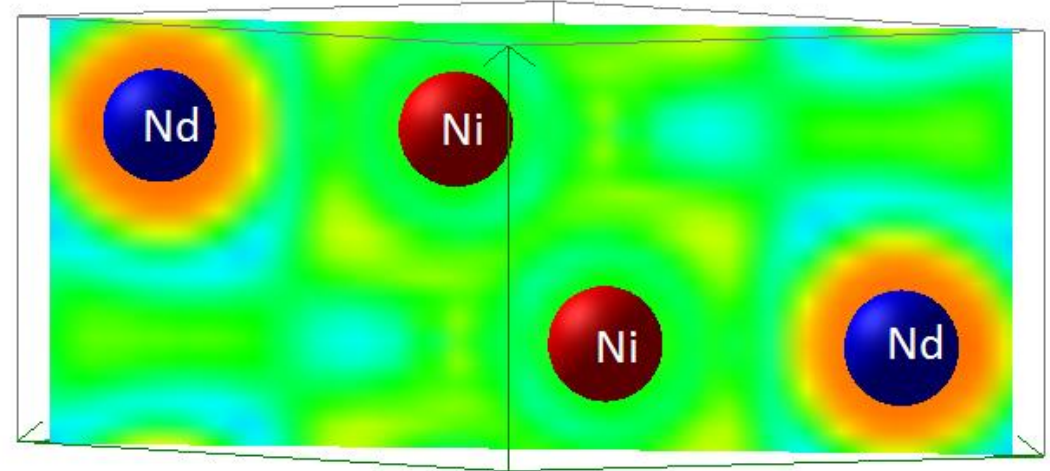

b) $\mathrm{NdNi}$

Fig. 2 

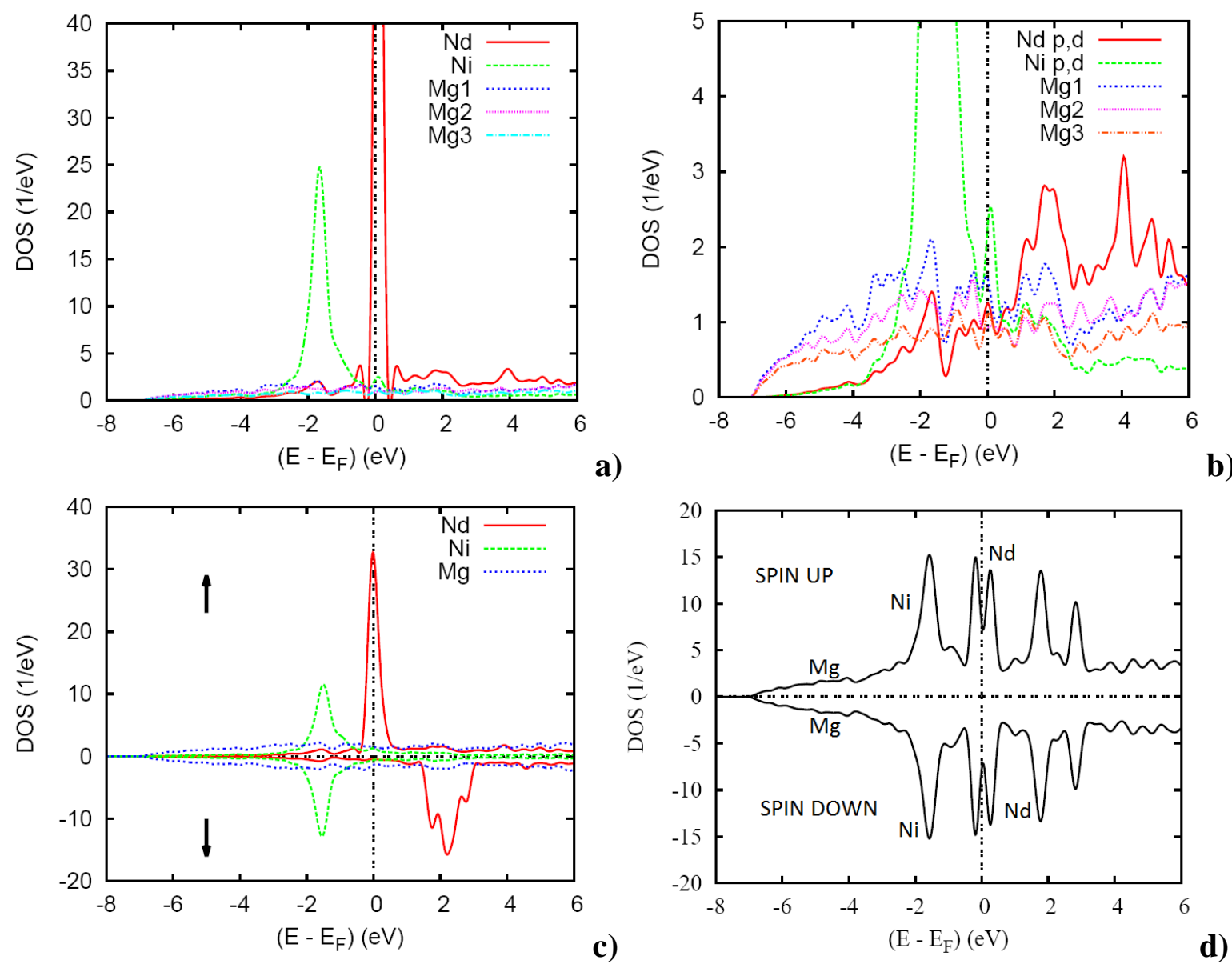

b)

Fig. 3 

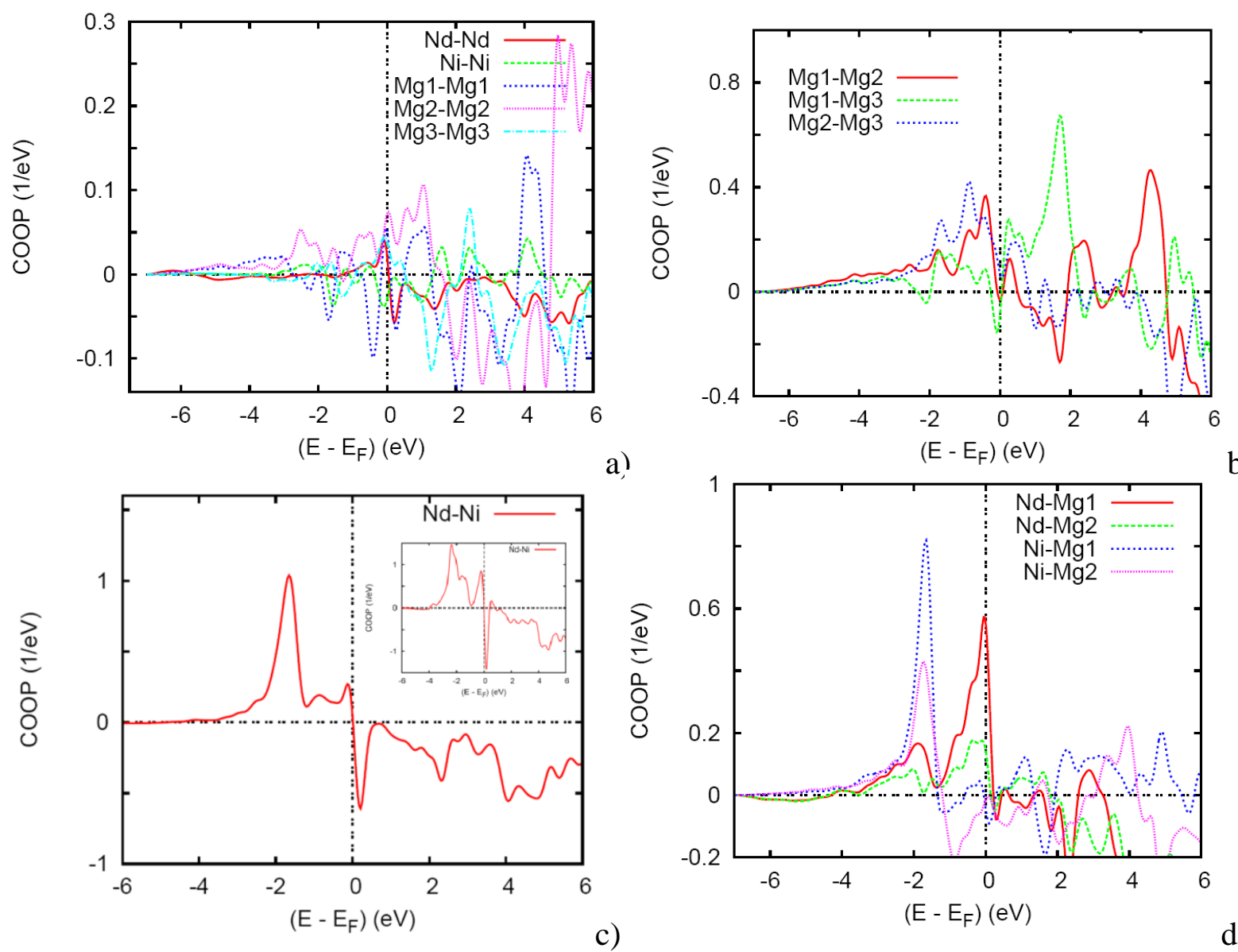

b)

d)

Fig. 4 